\title{
EL ESPACIO COMO PEDAGOGÍA
}

\section{Xenia Pacheco Soto}

El espacio es una construcción social e histórica y su organización no es neutra: responde a la lógica, las ideas y valores que la cultura jerarquiza como importantes y por tanto requiere de su reproducción para asegurar su continuidad. En ese sentido es que las configuraciones espaciales, de manera más bien implícita y metafórica, adquieren carácter de "pedagogías" que "instrumentalizan" esa reproducción. Tales configuraciones propician aprendizajes para la construcción de mentalidades proclives al mantenimiento y la propagación de dichos valores culturales, con adaptaciones y resistencias más o menos importantes, de acuerdo con las vivencias de cada persona y las características de su grupo social.

Las ideas que expongo a continuación tienen su apoyo teórico especialmente en los planteamientos de la geografía de 
la percepción y del género y su referencia empírica la constituye la configuración espacial de una casa que pertenece a una familia de clase media, en una de las ciudades del valle Central de Costa Rica. El análisis pretende desentrañar las interrelaciones entre dicha configuración y la reproducción de algunos de los valores de la cultura patriarcal como el confinamiento de las mujeres en sus casas, en términos reales y simbólicos, como veremos, en tanto mujeres-madres, guardianas de familias y de los binarismos adentro/afuera o exterioridad/interioridad y otros que se encabalgan a este esquema como naturaleza/cultura o privado/público.

\section{I}

Nuestra vida de todos los días discurre en interacción permanente con los espacios que habitamos. Mediante esas interacciones, que constituyen parte de la compleja trama en la que se organizan las relaciones sociales, participamos en la construcción social de esa coordenada fundamental para la vida que es la espacialidad.

El espacio geográfico es al mismo tiempo personal y social, como también es físico y mental. Cada ser humano le confiere los límites y significados que aprende de su grupo sociocultural y también los modifica de acuerdo con sus experiencias particulares, para que haya coherencia entre aquél y su forma de comprenderse a sí mismo (a) y al mundo. Así, las diversas maneras de construir los espacios, de interactuar con ellos, origina los conceptos que la geografía de la percepción denomina como "espacios vividos" o "espacios percibidos" de donde obtenemos el material para los mapas mentales personales, importantes que elaboramos para orientarnos y relacionarnos significativamente con nuestro entorno ( $\mathrm{Ca}$ pel, H. 1984). 
Habitar y construir espacios es, simultáneamente, un quehacer personal y social que tiene como sustrato las características de la cultura en la que se vive así como las condiciones sociales y personales de cada quien, tales como clase social, etnia, sexo, edad, escolaridad, entre otras. El espacio no es el mismo para mujeres que para hombres, para jóvenes que para ancianos, para analfabetas que para profesionales y si bien hay un cúmulo de aspectos referentes a la territorialidad que podrían ser compartidos, digamos, universalmente, también es cierto que las características mencionadas establecen interpretaciones, percepciones y significaciones diferenciadas acerca de la importante coordenada espacial.

Estas diferenciaciones han otorgado a la geografía de la percepción el material mediante el cual ésta explica la forma en que se organizan las percepciones espaciales, a partir de una esfera íntima, personal, que llama "espacio egocéntrico", al que se suceden los demás espacios, en una serie de esferas de amplitud creciente, aunque de finura perceptiva decreciente, conforme éstas se alejan de la persona y le son menos familiares. Es bueno aclarar que no existe acuerdo en cuanto al número, las características y el carácter concéntrico de tales esferas de percepción espacial (Capel, $\mathrm{H}$. 1973. Bosque, J., de Castro, C. et al. 1992).

En concordancia con lo anterior, habitar los espacios, vivirlos, es una experiencia estrechamente relacionada con la posibilidad de asignarles significados, así como de interpretar adecuadamente sus signos y símbolos, de acuerdo con los códigos que la cultura a la que pertenecemos, ha elaborado para realizar tal lectura. De esta manera, la vida cotidiana de cada persona tiene sentido, se "desplaza" fluida y coherentemente con la coordenada espacial, la cual asume como 
"natural" al punto de que se torna "invisible" para ella. Mientras esto sea así, sentiremos que el traslape entre vida cotidiana y espacialidad conforman un único paisaje, sin rupturas que interrumpan nuestro cotidiano discurrir: Nuestros sentidos percibirán las mismas informaciones para la elaboración de las imágenes espaciales familiares, que conforman nuestra esfera personal.

Por ejemplo, las habitaciones de nuestra casa, su disposición, forma, colores, texturas y olores; el vecindario con sus aceras e hitos de significación para nosotros como un parque, la pulpería de la esquina o el diseño arquitectónico de alguna casa y las partes de la ciudad por las que nos desplazamos, el plano que organiza su tráfico mediante el trazado de sus calles y avenidas, las aceras o alguna que otra edificación destacada.

\section{II}

En la cultura patriarcal las metáforas que más frecuentemente se utilizan para referirse a la casa probablemente sean aquellas que la señalan como el espacio de lo doméstico, el núcleo central de la femenidad, el sitio donde nos nutrimos afectiva y físicamente, el espacio del calor donde permanece, custodiado especialmente por la madre, el fuego del hogar. No obstante, lo anterior también tiene su "otro lado de la medalla" y la cotidianidad niega con mucha frecuencia, las románticas metáforas que se construyen acerca de la casa, evidenciando aspectos que ponen en tela de duda su calidad de "oasis de quietud", planteando entonces, fuertes contradicciones. Por ejemplo algunos autores afirman que la casa representa la naturaleza femenina establecida por el patriarcado como esencialmente fija e inmutable y que ésta retoma y expresa dicha esencia en su orden espacial 
unificado, cerrado e intemporal, con la figura materna como centralidad. Dicho orden se organiza mediante un proceso de domesticación espacial de los cuerpos individuales así como el de las familias, que le confiere a la casa características de espacio violento (Stephenson, M. 1998, p. 61 y ss.).

Siempre en esta misma línea argumental, Mark Wigley (1993), considera que el rol de la casa es el de proteger los derechos genealógicos del padre, al pretender, muchas veces con éxito, aislar a las mujeres de otros hombres para asegurarse que la reproducción sea sólo la del padre y su sitio sea la casa. Así, el confinamiento de las mujeres en el espacio de la casa, asegura, en el imaginario masculino, que la sexualidad de aquella puede ser controlada, "entre cuatro paredes", quedando la virtud de la mujer íntimamente ligada al sitio de la casa y a la interioridad que ésta representa para su cuerpo. Marcia Stephenson (1998) señala que los signos fundamentales de la mujer son "el cuerpo cerrado, la boca cerrada y la casa cerrada" y explica que la organización del espacio de las casas reproduce esas imágenes, mediante la promoción de la idea de que tal encierro confiere abrigo y resguardo seguro.

Por otra parte, en el espacio doméstico que representa la casa, se crea y reproduce la institución de la familia, tal y como la entiende la ideología patriarcal; en ella, la identidad de la mujer se desdibuja en tanto persona, para pasar a ser la "mujer-madre" que se asimila con el sitio fundante de la casa y el hogar. Ya sea que la familia se adhiera al modelo ideal elaborado por la cultura patriarcal o se exprese de otras maneras, lo cierto es que su lugar es la casa y su rol fundamental es, entre otros, participar en la socialización temprana de las hijas e hijos, modelándoles los respectivos roles genéricos de manera que éstos sean internalizados por aquéllos y formen 
parte de sus identidades genéricas correspondientes. En esta tarea juega un papel importante la configuración del espacio de la casa, el cual, por ejemplo, asigna habitaciones diferentes para cada género, de acuerdo con su posición en la estructura familiar. La ubicación de una puerta que separa y comunica, o de aposentos con mayor o menor exterioridad respecto de la calle, constituyen parte de la pedagogía espacial para los aprendizajes de la femenidad y la masculinidad. La casa está espacialmente organizada para la ejecución de tales aprendizajes: la semantización de su territorio, su tamaño y diseño, su decorado, por ejemplo, colaboran con nuestras primeras lecturas y memorizaciones de gestos, guiones, elección del vestuario, para esas primeras puestas en escena del género que culturalmente se nos ha asignado.

Así, los procesos pedagógicos mediante los cuales aprendemos a ser mujeres y hombres, encuentran apoyo didáctico en la configuración de los espacios internos y externos de la casa. Si recordamos, algunos de nuestros primeros "performances" del género que se nos asignó, los ejecutamos en nuestras casas, con la censura o los aplausos de la familia o quien la representara. Viene muy a cuenta en esta parte del análisis la profunda síntesis que Simone De Beauvoir (1987) hace en torno a la participación de la cultura en la construcción de los estereotipos genéricos: "No se nace mujer, llega una a serlo", la cual podría también aplicarse a los hombres y quizás hasta a otros tipos genéricos que se creen en el futuro.

La fuerte significación femenina de la casa desborda, también, los límites físicos de su construcción, para trasladar o ampliar sus significados fuera de ella, hacia espacios que podrían denominarse como espacios "morales". En este sentido, podría pensarse que los modales, hábitos y maneras 
"femeninas" ejecutadas fuera del ámbito físico de dicho inmueble, provocan una especie de trascendencia del mismo, de manera que mediante ese comportamiento particular, la mujer, aunque fuera de la casa, está dentro de ella, en tanto guarda las normas dictadas para su género, que contienen y expresan la moral patriarcal. La conducta catalogada culturalmente como "femenina" tiene como uno de sus ejes importantes a la "interioridad el "recogimiento", la "contención", muy relacionados con la simbolización de la casa cuyo espacio representa el sitio, por excelencia, de la interioridad.

Existe un sinnúmero de metáforas acerca del tema de la casa que han sido singularmente recogidas por refranes populares. Recordemos algunos de estos ejemplos de la sabiduría popular que ha sintetizado tales metáforas: "la casada, casa quiere", "la mujer en la casa y el hombre en la calle", "la madre es la reina del hogar", "la mujer y la casa, nunca terminan de arreglarse", "cada uno en su casa y Dios en la de todos", "la ropa sucia se lava en casa". Cada uno de ellos alude a alguna de las características que se asignan a la casa como espacio simbólico de lo femenino en la cultura patriarcal.

\section{III}

Hemos aprendido a organizar la realidad en grupos o esquemas binarios de opuestos excluyentes que conforman jerarquías en las que los lugares privilegiados corresponden a los hombres y lo masculino, en cambio los subvalorados a las mujeres y lo femenino. La organización de los espacios, incluidos, por supuesto, los de la casa, colabora con esta forma de comprender la realidad y de reproducirla. Así, por ejemplo, el grupo que corresponde a lo exterior o público donde se ubica y produce la cultura se asocia con lo masculino, mientras que sus opuestos como lo interior, privado o 
doméstico donde se halla la naturaleza, se asocia con las mujeres y lo femenino (Amorós, C.1983: pp.25-31).

La organización espacial, los usos a que predispone, las funciones que cumple, actúa como una pedagogía que de forma permanente y callada interviene en nuestros aprendizajes de la genericidad, legitimando y reproduciendo las valoraciones sociales que se asignan a cada territorio, según su connotación principal sea femenina o masculina.

Si aplicamos ese marco a la lectura espacial de la casa, podremos ir desentrañando los significados que subyacen a su construcción simbólica, que adquiere expresión física en su organización, diseño y arquitectura y que al mismo tiempo, predispone a sus funciones para el uso cotidiano, el cual incluye, además, las formas particulares de sentirla y vivirla. Así, en la interrelación cotidiana con tales espacios, las personas aprendemos a significarlos e interpretarlos, de manera que su ordenamiento adquiere el sentido que le conferimos desde nuestras propias interpretaciones de los esquemas culturales en los que hemos vivido. Las relaciones entre la configuración espacial, los usos que permita y el sentido que le damos deben ser coherentes y correspondientes; lo contrario origina tensiones y rupturas que alteran la continuidad simbólica, así como las formas de percibir y significar el espacio de la casa, con lo que sobrevendrían la pérdida de identidad espacial, la desorientación y el extrañamiento, con la consecuente dificultad para realizar la lectura del espacio y su interpretación.

Una de las expresiones más claras de la "complicidad" entre la casa y el aprendizaje de los esquemas dicotómicos, son las múltiples formas en que ese espacio delinea una serie de fronteras que refieren al binarismo mencionado, especialmente, como veremos, a aquellos que connotan exterioridad/ 
interioridad, afuera/adentro, abierto/cerrado, público/privado, naturaleza/cultura, que constituyen, como sabemos, principios ordenadores del territorio.

\section{IV}

Para encontrar las mencionadas "complicidades" entre los esquemas binarios de la cultura y la configuración espacial de las casas y ejemplificar cómo es que aquélla es una "pedagogía" para los aprendizajes acerca de los géneros, tracé un eje horizontal imaginario a lo largo de la planta edificada de una casa que pertenece a una familia de clase media del valle Central de Costa Rica, según lo expliqué párrafos atrás y asigné como límite exterior e interior de dicho eje a la calle y al patio, respectivamente ${ }^{1}$. El análisis de la localización de las habitaciones de la casa en relación con los límites del eje, evidencian que los aposentos vinculados con funciones o usos más relacionados con actividades femeninas tienen una situación más interior dentro de la vivienda, cercana al patio; en cambio aquellos más relacionados con actividades masculinas, encuentran una localización más exterior, próxima al límite externo, o sea a la calle. Entre los primeros están la cocina, la sala de lavado y planchado de la ropa que aparecen abiertamente comunicados con el patio, que estaría representando, en el contexto de la casa, el lugar de la naturaleza, por sus características de sitio despejado, algunas veces con vegetación, árboles o jardines interiores. Entre los segundos, veremos cómo a las habitaciones casi contiguas a la línea externa de construcción de la casa, se asignan usos masculinos, exteriores, sociales, como son las oficinas, consultorios, corredores o bien la sala y el comedor, en los que la familia "hace" vida social y se reciben

1 Este análisis sigue la orientación general planteada por el antropólogo español, Dr. Francisco Sánchez Pérez, en el capítulo III de su libro La lirurgia del espacio, pp. 41-70. (1990).

EnSAyos Pedagógicos-31 
las "visitas". La cercanía de estos aposentos con la calle, les confiere connotaciones que los ligan con lo público, lo exterior, el sitio de la cultura y por tanto, de los hombres.

El ejercicio anterior representa y reproduce también una visión estereotipada del espacio y sus significados de género. Por ello es importante aclarar que la organización de la estructura de las casas, en general, puede expresar otras formas de concebir las relaciones genéricas que podrían contradecir el esquema aquí planteado, mostrando así las tendencias que hoy día están tomando las nuevas formas de relación intergenéricas que contienen, en algunos ámbitos más que en otros, importantes cambios.

A tono con lo anterior, el análisis nos lleva a aclarar que si bien las configuraciones espaciales no son genéricamente neutras, éstas tampoco son unívocamente femeninas o masculinas. No significa que siempre un consultorio situado en el límite más externo de la casa va a representar a sus habitantes masculinos o que la cocina, por estar cerca de ese límite va a ser asignada como de ese género. Más bien son los comportamientos territoriales o espaciales de las personas y sus géneros los que determinan, en diferentes momentos, si un espacio es femenino o masculino, pero, lo que sí parece claro, es que el ámbito de exterioridad se asigna culturalmente a lo masculino y el de interioridad a lo femenino. Además, los lugares son femeninos o masculinos también de acuerdo también con las posiciones relativas que cada uno de los géneros tenga respecto del otro, cuidando siempre que no haya ni una posición ni una inversión de espacios de distinto género. Por ejemplo, la calle, considerada como el ámbito de lo masculino, podría "feminizarse" en horas de la mañana cuando las mujeres salen hacia sus trabajos, o bien a hacer sus compras, pero hacia la tarde y la noche casi 
siempre es considerada el "coto" masculino por excelencia. Hay también tendencias de exteriorización de las casas, expresados en los jardines que le rodean, sobre todo si en ellos trabajan las mujeres cuidando sus plantas, por ejemplo.

La multiplicidad de expresiones de la configuración espacial, que pueden incluso, contradecir o no los estereotipos de género, no invalida la cualidad del espacio como "pedagogía" que las contiene y comunica, evidenciando las diversas formas de organización social, las ideas y valores, los esquemas mentales, las maneras de ver el mundo y comprenderlo, que dan sentido a su propio ordenamiento. Se subraya así la importancia y utilidad del análisis espacial, en sus diferentes escalas y ámbitos, para identificar las tendencias sociales en los procesos de cambio, por ejemplo, los que señalan nuevas orientaciones hacia la construcción de relaciones genéricas democráticas y respetuosas.

\section{V}

Tales relaciones se expresan hoy en las formas y diseños de las casas, pudiéndose encontrar transformaciones que muestran el carácter diacrónico del ordenamiento espacial y en ese sentido, su permanente actualización como pedagogía para los nuevos aprendizajes de la genericidad.

Dichas transformaciones evidencian el importante acercamiento de las mujeres a los espacios públicos, las modificaciones en las concepciones tradicionales acerca de la familia y de los roles genéricos, todo lo cual ha provocado rupturas en la construcción y constitución de los paisajes cotidianos, tanto personales como sociales.

Si observamos con detenimiento la arquitectura de las casas, su distribución espacial, veremos que los sitios para la 
actividad intelectual, por ejemplo, son ahora compartidos por la pareja, así como por los hijos e hijas. Las cocinas, más pequeñas, evidencian que "la dueña de casa" no pasa ahí todo el día, que ya no es el espacio de reunión de la familia, sino que se le ha integrado, mediante diversos recursos del diseño arquitectónico, a las áreas sociales de la casa como el comedor y la sala. Los patios y jardines también se han sacrificado en cuanto a su tamaño, como corresponde a la lógica de la urbanización que propicia la densidad en el uso del suelo y lo encarece; pero esto también señala una separación de la casa del ámbito de la naturaleza: ya no tenemos en éstas, los enormes patios, sin tapias entre sí, muchas veces atravesados por acequias y poblados árboles frutales, que conferían un marcado acento rural al entorno y enriquecían las experiencias sensoriales de sus habitantes, con sonidos, sabores, texturas y dimensiones variadas y estimulantes.

El espacio es parte de la misma construcción social que elabora los contenidos diferenciados por género de la cultura, en la que participamos mujeres y hombres, cotidianamente. Observar su ordenamiento, levantando ligeramente el telón del escenario que nos parece tan familiar, natural y neutro, nos permite descubrir los hilos ocultos de su trama, de manera que la verosimilitud de la apariencia del paisaje da paso a la duda, a la incertidumbre y propicia nuevas lecturas, resignificaciones y aprendizajes. 


\section{BIBLIOGRAFÍA}

AMOROS, C. (1983): Hacia una crítica de la razón patriarcal. Paidós, Buenos Aires, Argentina.

BOSQUE, J., De CASTRO, C. et al. (1992): Prácticas de geografía de la percepción y de la actividad cotidiana. Oikos-Tau. Barcelona, España.

CAPEL, H.(1973): Percepción del medio y comportamiento geográfico. En Revista de Geografía, Vol. VII, Nos. 1-2. Barcelona, España.

CAPEL, H. y URTEAGA, L. (1984): Las nuevas geografías. Salvat. Barcelona, España.

DE BEAUVOIR, S. (1987): El segundo sexo. La experiencia vivida. Siglo $\mathrm{XX}$. Buenos. Aires, Argentina.

PACHECO, X. (1999): La generización del espacio. Dimensiones de una realidad oculta. En Revista Praxis N². 53, Departamento de Filosofía de la Universidad nacional, Heredia, Costa Rica.

(1997): El espacio del género en geografía. En Revista Geográfica de América Central, NN. 34 II Semestre de 1996-I Semestre de 1997. Escuela de Ciencias Geográficas de la Universidad Nacional. Heredia, Costa Rica.

SANCHEZ, F. (1990): El espacio y sus simbolos. Antropología de la casa andaluza. En Revista Española de Investigaciones sociológicas, №. 52, Octubre-Diciembre de 1990.

STEPHENSON, M. (1998): Hacia un análisis de la relación arquitectónica entre el género femenino y la raza en Bolivia. En Debate Feminista, Ciudad, Espacio y Vida. Año 9, Vol. 17. Abril de 1998.

WIGLEY, M. (1998): La deconstrucción del espacio. En Nuevos Paradigmas, Cultura y Subjetividad. Paidós Mexicana, México. 